\title{
Pandemi Döneminde Öğretmenlerin İş Yaşamı: Covid-19 Fobisi, İşten Ayrılma Niyeti ve Psikolojik Sermaye
}

DOI: 10.26466/opus.962907

$*$

\author{
Hikmet Hakan Coşkun* - Merve Mamac1 ${ }^{\text {** }}$ \\ * Uzm. Psk. İstanbul Kent Üniversitesi Lisansüstü Eğitim Enstitüsü, İstanbul/Türkiye \\ E-Posta: hikmethakancoskun@gmail.com \\ ORCID: $\quad$ 0000-0002-9429-549X \\ ** Dr., Fenerbahçe Üniversitesi, İktisadi İdari ve Sosyal Bilimler Enstitüsü İstanbul/Türkiye \\ E-Posta: merve.mamaci@fbu.edu.tr \\ ORCID: $\underline{0000-0001-7882-3670}$
}

Öz

Gerçekleştirilen bu araştırmada, Antalya ilinde çeşitli alanlarda ve düzeylerde öğretmenlik yapan kişilerin COVID-19 korkuları ve işten ayrılma niyetleri arasındaki ilişki incelenmiştir. Ayrıca; psikolojik sermayenin COVID-19 korkusu ve işten ayrılma niyeti arasındaki ilişkideki düzenleyici rolü test edilmiştir. Çalışmaya 312 öğretmen katılmıştır ve veriler katılımolardan çevrim içi ortam üzerinden ve elden dağıtılarak toplanmıştır. Araştırmadaki değgişkenlere ilişkin veriler demografik bilgi formu, Psikolojik Sermaye Ölçeği, COVID-19 Korkusu Ölçeği, İşten Ayrlma Niyeti Ölçeği kullanılarak elde edilmiştir. Yapılan analizler sonucunda; COVID-19 korkusu ile işten ayrılma niyeti arasında anlamlı ve pozitif yönde ilişki olduğuna dair bulgular saptanmıştır. Ayrıca; COVID-19 korkusu ile psikolojik sermaye arasında negatif yönde anlamlı ilişki bulunmuştur. Son olarak; işten ayrnlma niyeti ile psikolojik sermaye arasında negatif yönde anlamlı ilişki bulunmuştur. Yapılan düzenleyici değişken analizi neticesinde psikolojik sermayenin, COVID-19 ile işten ayrilma niyeti arasındaki ilişkide düzenleyici değişken rolünün olmadı̆̆ tespit edilmiştir. Bu tespitten yola çıkarak, güvenlik algısının yeterli olmadığı durumlarda psikolojik kaynaklardan biri olan psikolojik sermayenin koruyucu bir faktör olamayabileceği düşünülmüştür. Elde edilen bulgular, alan yazın çerçevesinde değerlendirilerek tartışılmıştır, gelecekte yapılacak çalışmalar için önerilerde bulunulmuştur.

Anahtar Kelimeler: Öğretmenler, Psikolojik Sermaye, Işten Ayrllma Niyeti, COVID-19 Fobisi, Pandemi. 


\title{
Teachers' Work Life During Pandemics: Covid-19 Phobia, Intention to Quit Job and Psychological Capital
}

\begin{abstract}
In this research, the relationship between the COVID-19 phobia and their intention to quit was examined. In addition, the moderator role of psychological capital in the relationship between COVID-19 phobia and intention to quit job was investigated. 312 teachers who work in Antalya in various fields and levels participated in the study and the data were collected from the participants via online and by hand. The data were obtained by using the demographic information form, the Psychological Capital Scale, the COVID19 Fear Scale, and the Intention to Leave Scale. Results showed that there is a significant and positive relationship between COVID-19 phobia and intention to quit job. In addition it has found that there is a negative significant relationship between the COVID-19 phobia and psychological capital. Also, a negative significant relationship was found between intention to quit job and psychological capital. Finally, it was found that psychological capital did not have a moderator variable role in the relationship between COVID19 and intention to quit job. Based on this result, it was thought that psychological capital, which is one of the psychological resources, may not be a protective factor in cases where the perception of physical security is not provided. The findings were evaluated and discussed within the framework of the literature, and suggestions were made for future studies.
\end{abstract}

Keywords: Teachers, Psychological Capital, Intention to Quit Job, Fear of COVID-19, Pandemics. 


\section{Giriş}

SARS - CoV -2 Pandemisi, Aralık 2019'dan itibaren küresel bir sağlik sorunu olarak (WHO, 2021) insanları duygusal, sosyal, bilişsel ve ekonomik yönden etkisi altına almıştır. Pandemi süreci bireylerin çalı̧̧ma yaşamlarına da nüfuz etmiştir. Bu süreçte aktif çalışma yaşamı olan bireyler, pandeminin kontrol altına alınmasına yönelik uygulanan kısıtlamaları ve önlemleri çalışma yaşamlarına adapte etmişlerdir. Alınan bu önlemler, çalışma yaşamını farklı şekillerde de olsa devam ettirebilmek ve çalışanların fiziksel bütünlüklerini ve sağlıklarını koruma altına almak için alınmış kararlardır.

Yamamoto ve Altun'a göre (2020) diğer sektörler kadar eğitim sektörü de COVID-19 salgın sürecinden etkilenmiştir. Örnek vermek gerekirse, salgının kontrol altına alınması ve bulaşın engellenmesi için okullarda çeşitli önlemler alınmıştır. Sınıflarda sosyal mesafe kurallarına uymanın zor olması ve sosyal izolasyonun bulaşı engelleyici bir faktör oluşu sebebiyle eğitimde yüz yüze öğretime ara verilerek uzaktan eğitim yöntemine geçilmiştir. Öte yandan, eğitim sisteminin çevrim içi platformda sürdürülmesi sağlık sisteminin korunması, öğretmenlerin ve öğrencilerin sağlıklarının güvence altına alınması açısından faydalı olsa da eğitim faaliyetlerinin uzaktan öğrenme ile verimli bir şekilde devam edemeyeceği gündeme gelmiştir (TRT, 2020). Eğitimin verimliliğinden ve etkinliğinden yola çıkarak, eğitim sektöründe kısıtlamalar tekrar değerlendirilmiş ve eğitim alanında 2021 yılı Mart ayı ikinci dönemde kademeli olarak yüz yüze eğitime geçilmiştir (MEB, 2021). Kovid-19 Aşı11 Ulusal Uygulama Stratejisi bağlamında öğretmenlerin aşılamasına 6 Haziran 2021' de başlanmıştır (Selçuk, 2021).

Yüz yüze eğitime geçiş ve aşılanma tarihleri değerlendirildiğinde öğretmenlerin aktif olarak yüz yüze eğitim verirlerken aşılanmadıkları görülmektedir. Bu sebeple, öğretmenlerin COVID-19 pandemisine bağlı olarak kendilerini tehdit altında hissedebilecekleri ve mesleklerinden ve/veya bağlı oldukları kurumlardan ayrılmayı düşünebilecekleri varsayılarak bu araştırmada öğretmenlerin COVID-19 korku düzeyleri ile işten ayrılma niyetleri arasındaki ilişki test edilmiştir.

Özellikle pandemi dönemi gibi zor bir dönemde bireyleri güçlü kılan psikolojik faktörlerin araştırılması önem taşımaktadır. Bu faktörlerden 
biri psikolojik sermayedir. Luthans, Luthans ve Luthans (2004) psikolojik sermayenin birey için önemli olabilecek diğer sermayelerin ötesinde bir kavram olduğunu ve kişiye özgü pozitif bir yapı olduğunu ifade etmektedirler. $\mathrm{Bu}$ noktadan hareketle, COVID-19 korkusu ve işten ayrılma niyeti arasındaki ilişkide psikolojik sermayenin düzenleyici rolünün test edilmesinin, Türkiye'de eğitim alanında alınacak önlemlere ve öğretmenlerin fizyolojik ve psikolojik ihtiyaçlarının giderilmesine ve eğitim sektörünün geliştirilmesine olumlu yönde katkı sağlayacağ1 düşünülmüştür. Ayrıca, pandemi döneminde aktif çalışma yaşamı olan öğretmenlerin psikolojik sermaye seviyelerinin tespit edilmesi ve COVID19 korkusu ile işten ayrılma niyetleri arasındaki ilişkide psikolojik sermayenin düzenleyici rolünün test edilmesinin, öğretmenlerin psikolojik sermaye düzeylerinin artırılmasına yönelik eğitimlerin oluşturulması için araştırma temelli bir zemin sağlayacağ ümit edilmiştir.

\section{Kavramsal Çerçeve}

Tüm dünyaya yayılan, tüm ülkeleri ve bölgeleri etkileyen COVID-19 pandemisinde salgından bireysel olarak korunmaya ve salgını kontrol altına almaya yarayacak stratejiler önerilmiştir ve bu stratejiler; el yıkamak, yüz maskesi takmak, fiziksel mesafe koymak, toplu alanlardan sosyal toplantılardan kaçınmak ve evde kalmaktır (Sintema, 2020). COVID-19 salgınına bağlı olarak sosyal yaşamda uygulanması önerilen sağlıklı davranış stratejilerinin ve kriz yönetimi uygulamalarının ülkelerin eğitim sistemlerini, öğretmenleri, öğrencileri ve ailelerini de fizyolojik, psikolojik ve sosyal açıdan etkilediği görülmektedir. Etkilenen alanlardan biri de eğitim alanıdır. Okulların yüz yüze eğitime ara vermesi, eğitimde uzaktan öğrenme modelinin ve dijital öğrenmenin büyük ölçüde hayata geçirilmesi gündeme gelerek eğitim sisteminde çeşitli değişiklikler gerçekleşmiştir (TRT, 2020). Kısıtlamalar sonrasında kademeli olarak okulların yeniden açılmasıyla birlikte farklı zorlukların da ortaya çıkabileceği düşünülebilir. Örneğin sınıf ortamında yeterli izolasyonun sağlanamaması, sinıflarda temaslı kişilerin olma ihtimali ve kurumda ya da sınıfta semptom göstermeyen COVID-19 vakalarının olma ihtimali, öğretmenlerde COVID-19 kaynaklı korkuya ve endişeye neden olabilir. 
Alan yazın incelendiğinde COVID-19 korkusunun üç farklı bileşenden oluştuğu belirtilmektedir. Bu bileşenlerden ilki olan fizyolojik bileşendir; virüs korkusu olan kişiler savaşma ya da kaçma tepkisi gösterirler. Bu tepkiyle birlikte bireyler çarpıntı, titreme, nefes almada zorluk, baş dönmesi, iştah değişikliği ve uyku gibi semptomları yaşayabilirler (Wang ve diğerleri, 2020). İkinci bileşen ise bilişsel bileşendir; virüs korkusu olan bireylerde, virüs tehdidi içeren bilişlerle sürekli meşgul olabilirler (Chakraborty ve Chatterjee, 2020). Örneğin; “virüs bulaşırsa ölürüm, virüs bulaşmaması için işe gitmemem gerekiyor, virüsten dolayı işe gidemeyeceğim ve işsiz kalacağım, ailem ve sevdiklerim virüsten dolayı tehdit altında" gibi çeşitli tehdit içeren bilişler bireylerde ortaya çıkabilir. COVID-19 korkusunun üçüncü bileşeni olan davranışsal bileşene göre ise COVID-19 korkusu olan bireylerde, olası olumsuz sonuçları önlemek için kaçınma davranışları ortaya çıkabilmektedir. Bu kaçınma davranışları toplu taşımayı kullanmamayı, herhangi bir yüzeye dokunmamayı, açık ve/veya kapalı yerlerde olmamayı, halka açık herhangi bir toplantıya katılmamayı içerebilir (Tanner, 2020). Bireyler, insanlarla bir araya gelmeyi içeren durumlardan korkabilir ve kaçınabilirler. Ayrıca sağlıkla ilgili güvenlik davranışlarına aşırı düşkün olabilirler. Bu davranışlar; ellerini sürekli yıkamak, vücudun hayati değerlerini sürekli kontrol etmek, hasta olmadığının sürekli doğrulama ihtiyacını ve kendi kendine ilaç kullanma davranışı olarak ortaya çıabilir. Bahsedilen bu güvence verme davranışları kaygıyı anlık olarak azaltsa da aslında korkuyu sürdürerek fobiye yol açabilmektedir (Li ve diğerleri, 2020).

Özgül fobi bozukluğuna sahip olan bireyler, günlük işlevselliklerini gerçekte var olan ya da hayal edilen nesneye ya da duruma karşı sürekli ve irrasyonel korku hissederek, kaçınma ve kaçma davranışı göstererek sekteye uğratabilirler (Eaton ve ark., 2018; Ruiz-García ve Valero-Aguayo, 2020). Her ne kadar virüse ilişkin gelişen korku gerçekçi olsa da bu korku bireyin günlük işleyişinin genel kalitesini ve kişinin fonksiyonelliğini bozabilir. Bu bilgilerden yola çıkarak öğretmenlerin COVID-19 korkusuna bağlı olarak okula gitmekten kaçınabilecekleri ve işten ayrılmaya niyet edebilecekleri varsayılabilir (H1: COVID-19 korkusu ile işten ayrılma niyeti arasında anlamlı ve pozitif yönde bir ilişki vardır).

Kurumların büyümesi, üstlendiği faaliyetler, kurumların faaliyet gösterdiği işteki başarısı, çalışanlarının aldığı karara ve sergiledikleri 
davranışa bağlıdır (Mello, 2011). Birçok alanda çalışma yaşamı olan kişilerin kendi istekleri doğrultusunda işten ayrılma niyetleri, araştırmacılar tarafından sıklıkla araştırılmıştır (Griffeth, Hom ve Gaertner, 2000; Hom ve Kinicki, 2001). İşten ayrılma niyeti ile ilişkili tanımlar alan yazın çerçevesinde incelendiğinde, işten ayrılma ile ilgili farklı yazarların farklı tanımları ve açıklamaları olduğu görülebilmektedir. Örneğin; Tett ve Meyer (1993) işten ayrılma niyetini çalışanın devamlı ve bilinçli bir biçimde planlı olarak bulunduğu kurumdan ayrılma isteği ve bu isteğe bağlı olarak ortaya çıkan ayrılma kararı ile tanımlamaktadır. Bir başka açıklamada ise işten ayrılma niyeti, çalışanın bilinçli olarak çalıştığ tanımlanmaktadır (Cho ve arkadaşları, 2009). Rusbult ve arkadaşlarına göre (1988) işten ayrılma niyeti yıkıcı bir eylemdir ve çalışanlar işlerinden memnun olmadıklarında bu aktif eylemi gerçekleştirebilirler. İşi bırakma niyeti, hali hazırda var olan iş yerini bırakma ve yakın gelecekte başka iş arayışı içinde olma şeklinde de tanımlanmaktadır (Masroor ve Fakir, 2010).

Alan yazında işten ayrılma niyetinin arkasındaki değişkenler bireysel, örgütsel ve dış faktörler olarak gösterilmektedir. İşten ayrılma niyetinin arkasındaki bireysel değişkenler; yaş (Joseph, Ng, Koh ve Ang, 2007), cinsiyet (Ghapanchi ve Aurum, 2011), eğitim düzeyi (Moynihan ve Landuyt, 2008), medeni durum (Igbaria ve McCloskey, 1996), aile veya aile bireylerine olan sorumluluk ve mesleki deneyim (Mobley, Griffeth, Hand ve Meglino, 1979) olarak ifade edilmektedir. İşten ayrılma niyetinin ikinci öncülü olan örgütsel faktörler alan yazın çerçevesinde incelendiğinde, iş tatmininin ve örgütsel bağl1lı̆̆ın ele alındığ1 görülmektedir (Hoppock, 1935; Meyer ve diğerleri, 1997). İşten ayrılma niyetinin yordayıcısı olarak ele alınan dış faktörler ise, kurumun dışında kalan faktörlerden oluşmaktadır. Bu diş faktörler kurumla ilişkili olsa da direkt olarak kuruma dahil değildirler. Kurum haricindeki uyaranlar ve gerçekleşen sosyal, ekonomik, politik öğeler olarak değerlendirilebilecek bu faktörlerin de çalışan bireylerin işten ayrılma niyetlerinde rol oynadığ 1 düşünülmektedir (Nancarrow ve diğerleri, 2014; Heinen ve diğerleri, 2013; Lee ve Mitchell, 1994). Bu bilgilerden yola çıkarak dünya çapında ülkeleri, ülkelerin sağlık sistemlerini, bireyleri etkileyen COVID-19 
pandemisinin de dış faktör olarak değerlendirilebileceği ve işten ayrılma niyetinin ortaya çıkmasında etkili olduğu düşünülebilir.

Martin Seligman ve Csikszentmihalyi (2000) tarafından "pozitif insan işleyişinin ve gelişiminin biyolojik, bireysel, ilişkisel, kurumsal, kültürel ve küresel düzeylerde bilimsel açıdan incelenmesi" olarak tanımlanan Pozitif Psikoloji hareketinin gündeme gelmesi ve yaygınlaşması ile bireyin olumlu özelliklerine olan ilginin arttı̆̆ı görülmektedir. Bu ilgi aynı zamanda örgütsel psikoloji ve pozitif örgütsel davranış alanlarına da ilham vererek psikolojik sermaye kavramının aynı zamanda iş yaşamına entegre olmasını sağlamıştır. İş yaşamında da sıklıkla incelenen psikolojik sermaye kavramının aynı zamanda bireylerin sağlığı ile de ilişkili olduğu çeşitli araştırmalarda ortaya koyulmuştur (Estiri, Nargesian, Dastpish ve Sharifi, 2016).

Alan yazın incelendiğinde psikolojik sermayenin "günümüz işyerlerinde performansın iyileştirilmesi için ölçülebilen, geliştirilebilen ve etkili bir şekilde yönetilebilen pozitif yönelimli insan kaynaklı güçlü yönlerin ve psikolojik kapasitelerin incelenmesi ve uygulanması" olarak tanımlandığı görülmektedir (Luthans, 2002). Bu tanımdan yola çıkarak bir bireyin psikolojik sermaye durumunun dört farklı öğenin bileşimi olarak karakterize edildiği görülmektedir: Bu bileşenler; (1) özyeterlik: zorlu görevlerde başarılı olmak için gerekli çabayı gösterme ve üstlenme konusunda kendine güveninin olması; (2) iyimserlik: şimdi ve gelecekte başarılı olma konusunda olumlu bir atıfta bulunması; (3) umut: başarıya ulaşmak için hedeflere doğru sebat etmesi ve gerektiğinde hedeflere giden yolları yeniden yönlendirmesi; ve (4) psikolojik dayanıklılık: sorunlar ve güçlüklerle kuşatıldığında, başarıya ulaşmak için çabayı sürdürmesi, geri dönmesi ve hatta ötesine geçmesi olarak belirtilmektedir (Luthans, Youssef ve Avolio, 2007).

Avey ve arkadaşları (20211) tarafından gerçekleştirilen meta-analiz çalışmasında psikolojik sermayenin iş tatmini, psikolojik iyi oluş, örgütsel bağlılık ve performans ile anlamlı ve pozitif yönde ilişkili olduğu ve iş stresi, işten ayrılma niyeti ile negatif yönde ilişkili olduğu gösterilmiştir. Bir diğer araştırmaya ise 416 çalışan katılmıştır ve psikolojik sermayenin stres belirtilerini azaltmada ve işten ayrılma niyetlerini azaltmada temel bir bilişsel kaynak olduğu ortaya çıkmıştır (Avey ve ark., 2009). Pandemi döneminde gerçekleştirilen bir diğer araştırmada 290 kişinin psikolojik 
sermaye düzeyleri ile depresyon, anksiyete ve yaşam doyumu düzeyleri arasındaki ilişki test edilmiştir. Araştırma sonuçları psikolojik sermayenin depresyon ve anksiyete ile anlamlı ve negatif yönde ilişkili olduğunu ortaya koymuştur (Turliuc ve Candel, 2021).

Alan yazın çalışmalarından yola çıkıldığında ve psikolojik sermaye birey için güçlü bir özellik olarak değerlendirildiğinde, psikolojik sermayenin yükselmesiyle COVID-19 korkusu ve işten ayrılma niyeti arasındaki ilişkinin azalması beklenebilir. Bu sebepten, bu araştırmada psikolojik sermayenin COVID-19 korkusu ve işten ayrılma niyeti arasındaki ilişkide düzenleyici değişken olup olmadığı test edilmiştir $(\mathrm{H} 2$ : COVID-19 ile işten ayrılma niyeti arasındaki ilişkide psikolojik sermaye düzenleyici değişkendir. Şöyle ki, psikolojik sermaye yükseldikçe COVID-19 korkusu ve işten ayrılma niyeti arasındaki ilişki azalacaktır).

\section{Yöntem}

\section{Evren ve Örneklem}

Araştırmanın evreni öğretmenlerden oluşmaktadır. Örneklemi ise, okul öncesi, ilkokul, ortaokul ve lise aşamalarında eğitim veren, araştırmaya gönüllü katılan 312 (yaş ort=42.71; ss=9.874) katılımcıdan oluşmaktadır. Araştırmaya katılan öğretmenlerin \%48.4'ü kadın ( $\mathrm{n}=151$; yaş ort=40.70; $\mathrm{ss}=9.922)$ ve \%51.6's1 erkektir ( $\mathrm{n}=161$; yaş ort=44.59; $\mathrm{ss}=9.480)$.

\section{Veri Toplama Araçları}

Veriler; İstanbul Kent Üniversitesi, Sosyal ve Beşeri Araştırma ve Yayın Etiği Kurulu tarafından, 26.03.2021 tarihinde, araştırmanın yöntemine dair anket sorularının uygulanmasının etik olarak uygun olduğuna dair oy birliği ile verilen karar doğrultusunda toplanmıştır.

\section{Demografik Bilgi Formu}

$\mathrm{Bu}$ form, katılımclara ilişkin demografik bilgilerin sorulduğu, araştırmacı tarafından hazırlanmış bir kişisel bilgi formudur. Formda cinsiyet, yaş, 
medeni durum, çocuk, eğitim, çalışma durumu ile ilişkili değişkenler hakkında sorular sorulmuştur.

\section{Psikolojik Sermaye Ölçeği}

$\mathrm{Bu}$ araştırmada, Psikolojik Sermayeyi ölçmek amaciyla Luthans, ve diğerleri (2007) tarafından geliştirilip, Çetin ve Basım, (2012) tarafından Türkçe uyarlama çalışması yapılan Psikolojik Sermaye Ölçeği kullanılmıştır. Ölçekte, toplam 24 madde yer almaktadır ve Likert tipinde hazırlanmıştır. Ölçeğin alt boyutlar; umut, iyimserlik, özyeterlik ve psikolojik dayanıklılıktır. Ölçeğin alt boyutlarının Cronbach Alpha katsayılarının sırasıyla; .74, .76, .73 ve .71 olduğu tespit edilmiştir. Ölçeğin iç tutarlılık Cronbach Alpha katsayısı ise .90 olarak bulunmuştur.

\section{İşten Ayrılma Niyeti Ölçeği}

Bu araştırmada Rosin ve Korabik'in (1995) geliştirdiği Likert tipinde hazırlanmış ve güvenirlik çalışması Elmas (2012) tarafından yapılan İşten Ayrılma Ölçeği kullanılmıştır. Ölçekte 4 ifade bulunmaktadır ve ölçekte bulunan ifadelere verilen cevaplar 5'li Likert ölçeğinde değerlendirilmektedir. Ölçek tek faktörlüdür. Katılımcıların işten ayrılma niyeti ölçeğinden aldıkları puan arttıkça, işten ayrılma niyetleri artmaktadır. Bu araştırmanın örneklemi için ölçeğin iç tutarlılık Cronbach Alpha katsayısı .84 bulunmuştur.

\section{Covid-19 Korkusu Ölçeği}

Kişilerin COVID-19'dan kaynaklanan korku seviyelerinin ölçülmesi amacıyla Ahorsu ve arkadaşları (2020) tarafından geliştirilmiştir ve ölçeğin Türkçe geçerlik ve güvenilirlik çalışması Ladikli ve arkadaşları tarafından 2020 yılında yapılmıştır. Ölçek tek faktörlü yapıdadır ve beşli Likert ölçeğinde değerlendirilmektedir. Bu araştırmanın örneklemi için ölçeğin iç tutarlılık Cronbach Alpha katsayısı .89 bulunmuştur.

\section{Verilerin Analizi}


Araştırmada elde edilen veriler SPSS v.21 istatistik programı ile istatistiksel analize tabi tutulmuştur. Öncelikle, araştırmada kullanılan ölçeklerden alınan puanlar için Kolmogorov-Smirnov ve Shapiro-Wilk normal dağılım testleri yürütülmüştür ancak normal dağılım gözlenmemiştir. Tabachnick ve Fidell'in (2013) önerdiği gibi çarpıklık ve basıklık (Skewness-Kurtosis) değerlerinin \pm 1.5 aralığında olup olmadıkları incelenmiş ve ölçeklerden alınan puanların çarpıklık ve basıklık değerlerinin \pm 1.5 aralığında oldukları gözlendiğinden puanların normal dağılım gösterdiği kabul edilmiştir. Bundan dolayı, istatistiksel analizler parametrik testlerle yürütülmüştür. Puanların normal dağılım gösteriyor olması nedeniyle korelasyon analizlerinde Pearson korelasyon analizi yürütülmüş, ayrıca normal dağılım sağlandığından regresyon analizleri de yürütülebilmiştir.

\section{Bulgular}

\section{Demografik bulgular}

Öğretmenlerin yaş ortalamaları 42.71; bulundukları iş yerindeki toplam çalışma süresi ortalamaları $6.47 \mathrm{y}$ 1, toplam iş deneyimi süresi ortalamaları 18.70 yıl bulunmuştur. Öğretmenlerin \%14.7' sinin bekar, \%85.3'ünün evli olduğu; \%81.4'ünün çocuğunun olduğu, \%17.6'nin, \%0.6'sının hem çocuğunun olduğu hem de bebek bekledikleri, \%0.3'ünün ilk çocuklarını bekledikleri; \%82.1'nin lisans, \%17'sinin yüksek lisans, \%1'nin doktora mezunu olduğu; \%75'nin devlet okulunda, \%25'inin özel okulda çalıştığı; \%90.1'nin tam zamanlı, \%9.9'unun yarı zamanlı çalıştığ1; \%2.9'unun okul öncesinde, \%25.3'ünün ilkokul kademesinde, \%19.6'sinin ortaokul kademesinde, \%52.2' sinin lise kademesinde çalıştığ $1 \%$ \%8.2'sinin pandemi sürecinde uzaktan eğitim verdiği, \%12.8'nin uzaktan eğitim vermediği; \%9.3'ünün COVID-19 geçirdiği, \%90.7'sinin geçirmediği; \%71.8'inin yakınının COVID-19 geçirdiği, \%28.2'sinin geçirmediği saptanmıştır. 


\section{Korelasyon Analizi}

Regresyon analizi ile düzenleyici değişken analizine geçilmeden önce bağımsız değişken, bağımlı değişken ve düzenleyici değişken arasındaki ilişkilerin incelenmesi için Pearson korelasyon analizi yürütülmüştür.

Tablo 1 'de öğretmenlerin Psikolojik Sermaye Ölçeğinden, COVID-19 Korkusu Ölçeğinden ve İşten Ayrılma Niyeti Ölçeğinden aldıkları puanlar arasındaki Pearson korelasyon analizi bulguları verilmiştir.

Tablo 1. Araştırma Değişkenleri Arasındaki Korelasyon Matrisi

\begin{tabular}{lccccccc}
\hline \multicolumn{1}{c}{} & $\mathbf{1}$ & $\mathbf{2}$ & $\mathbf{3}$ & $\mathbf{4}$ & $\mathbf{5}$ & $\mathbf{6}$ & $\mathbf{7}$ \\
\hline 1. Covid-19 Korkusu & 1 & & & & & & \\
2. İşten Ayrılma Niyeti &. $\mathbf{2 0 6 ^ { * * }}$ & 1 & & & & & \\
3. Psikolojik Sermaye & $-.190^{* *}$ & $-.179^{* *}$ & 1 & & & & \\
4. İyimserlik & $-.219^{* *}$ & $-.331^{* *}$ & $.778^{* *}$ & 1 & & & \\
5. Psikolojik Dayanıkl1lk & $-.230^{* *}$ & -.098 & $.898^{* *}$ & $.593^{* *}$ & 1 & & \\
6. Umut & -.076 & $-.115^{*}$ & $.890^{* *}$ & $.568^{* *}$ & $.747^{* *}$ & 1 & \\
7. Özyeterlik & $-.113^{*}$ & -.046 & $.842^{* *}$ & $.446^{* *}$ & $.726^{* *}$ & $.729^{* *}$ & 1 \\
\hline
\end{tabular}

${ }^{*} p<.05 ;{ }^{* *} p<.01$

Öğretmenlerin COVID-19 korkusu puanları ile işten ayrılma niyeti puanları arasında pozitif yönde düşük düzeyde anlamlı ilişki bulunmuştur ( $r=.206 ; \mathrm{p}=.000)$. Öğretmenlerin COVID-19 korkusu puanları ile psikolojik sermaye toplam puanları arasındaki ilişki test edildiğinde, negatif yönde düşük düzeyde anlamlı ilişki bulunmuştur ( $\mathrm{r}=-.190 ; \mathrm{p}=.001)$. Bir diğer deyişle; psikolojik sermaye düzeyi azaldıkça COVID-19 korkusu artmaktadır. Son olarak; işten ayrılma niyeti ile psikolojik sermaye toplam puanı arasında negatif yönde düşük düzeyde anlamlı ilişki bulunmuştur $(\mathrm{r}=-.179 ; \mathrm{p}=.001)$. Bu sonuç; psikolojik sermeye düzeyinin azalmasıyla işten ayrılma niyetinin arttığına işaret etmektedir. 


\section{Düzenleyici Değişken Analizi}

Şekil 1'de düzenleyici değişken analizine girecek değişkenlere ilişkin model sunulmuştur.

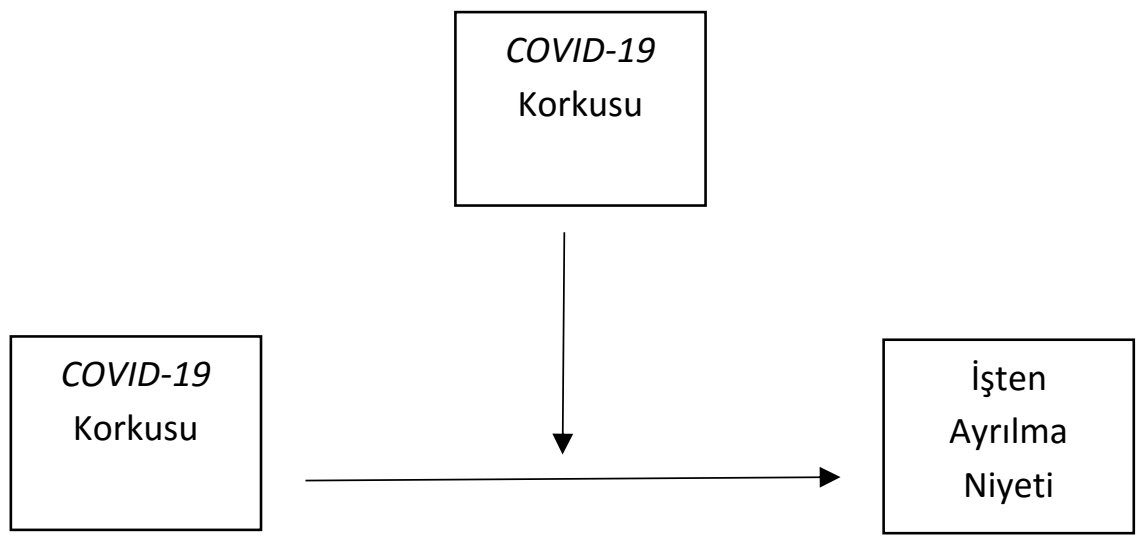

Şekil 1 COVID-19 İle İsten Ayrılma Niyeti Arasındaki İlişkide Psikolojik Sermayenin Düzenleyici Etkisine İlişkin Model

Regresyon analizlerine geçilmeden önce etkileşim teriminin hesaplanması yapılmıştır. Etkileşim teriminin hesaplanması için düzenleyici değişken ve bağımsız değişkenin çarpımı alınarak yeni bir değişken yaratılmıştır. Bu çarpım işlemi yapılmadan önce ise çarpımdan oluşan büyük rakamlar ve aşırı yüksek korelasyonlar yani çoklu bağlantı probleminin engellenmesi için merkezileştirme işlemi yapılmıştır. Bağımsız değişken $(X)$ ve düzenleyici değişkenin $(M)$ her biri için katılımcların ham puanlarından grubun ortalaması çıkartılarak yeni değişkenler oluşturulmuştur:

$X-X^{-}=\mathrm{CX} \quad$ : Merkezileştirilmiş bağımsız değişken formülü

$\mathrm{M}-\mathrm{M}^{-}=\mathrm{CM} \quad$ : Merkezileştirilmiş düzenleyici değişken formülü

Merkezileştirilmiş yeni değişkenlerin çarpımı alınarak $\mathrm{c}^{*} \mathrm{cM}$ etkileşim terimi yaratılmış ve regresyon analizinde bağımlı değişken $(\mathrm{Y}), \mathrm{cX}, \mathrm{cM}$ ve $\mathrm{cX}^{*} \mathrm{cM}$ bağımsız değişkenler olarak regresyon modeline sokulmuştur.

Tablo 2'te COVID-19 korkusu ile işten ayrılma niyeti arasındaki ilişkide psikolojik sermayenin düzenleyici etkisine ilişkin standart regresyon analizi bulguları verilmiştir. 
Tablo 2. COVID-19 Korkusu İle İşten Ayrılma Niyeti Arasındaki İlişkide Psikolojik Sermayenin Düzenleyici Etkisine İlişkin Standart Regresyon Analizi Bulguları

\begin{tabular}{lllllllll}
\hline Model & Değişken & $\mathbf{R}$ & $\mathbf{R}^{2}$ & $\mathbf{B}$ & $\mathbf{B}_{\mathrm{sh}}$ & $\boldsymbol{\beta}$ & $\mathbf{t}$ & $\mathbf{F}$ \\
\hline \multirow{2}{*}{1} & Sabit & & & 7.763 & .247 & & 31.450 & \\
& Covid-19 Korkusu & \multirow{2}{*}{.252} & .064 & .111 & .036 & .175 & $3.115^{*}$ & \\
& Psikolojik Sermaye & & & -.045 & .017 & -.149 & $-2.638^{*}$ & $6.984^{*}$ \\
& Etkileşim Terimi & & & .001 & .002 & .032 & .580 & \\
\hline
\end{tabular}

${ }^{*} p<.01$

Bağımsız değişken ve düzenleyici değişkenin bağımlı değişken üzerindeki etkisinin yordanması amacıyla yürütülen standart regresyon analizinde, bağımlı değişken (Y) işten ayrılma niyeti, bağımsız değişken (X) COVID-19 korkusu ve düzenleyici değişken (M) psikolojik sermaye olup, regresyon analizinde bağımsız değişken ve düzenleyici değişkenlerin merkezileştirilmiş biçimlerinin çarpımından oluşan etkileşim terimi de modele eklenmiş ve standart regresyon analizi yürütülmüştür.

Regresyon analizi sonucunda elde edilen modelin $[F(3-308)=6.984$; $\mathrm{p}<.01]$ anlamlı olduğu; modelde işten ayrılma niyeti bağıml değişkenindeki varyansın \%6'sının bağımsız değişken COVID-19 korkusu, düzenleyici değişken psikolojik sermaye ve hem bağımsız hem de düzenleyici değişkenin etkileşimiyle açıklandığı ( $\mathrm{r}=.253$; r2=.064); COVID-19 korkusunun [ $\mathrm{t}=3.115 ; \mathrm{p}<.01]$ ve psikolojik sermayenin [ $\mathrm{t}=-2.638$; $\mathrm{p}<.01]$ işten ayrılma niyetini yordadığ 1 ancak bu iki değişkenin etkileşiminin işten ayrılma niyetini anlamlı şekilde yordamadığ ${ }_{1}(\mathrm{t}=.580$; p>.05) tespit edilmiştir. Dolayısıyla COVID-19 korkusu ile işten ayrılma niyeti arasındaki ilişkide psikolojik sermayenin düzenleyici etkisinin olmadığı bulunmuştur. 


\section{Tartışma ve Sonuç}

Bu çalışma Antalya ilinde çalışan öğretmenlerin, COVID-19 korkuları ve işten ayrılma niyetleri arasındaki ilişkide psikolojik sermayenin düzenleyici rolünün incelenmesi amacıyla gerçekleştirilmiştir. Yapılan korelasyon analizi bulguları, COVID-19 korkusu ile işten ayrılma niyeti arasında anlamlı ve pozitif yönde bir ilişki olduğunu ortaya koymuştur. Bir diğer deyişle ilk hipotez doğrulanmıştır (H1: COVID-19 korkusu ile işten ayrılma niyeti arasında anlamlı ve pozitif yönde bir ilişki vardır).

Alan yazın incelendiğinde, farklı örneklemlerle yapılan araştırmalarda pandemi döneminde çalışanların COVID-19 korkuları ile işten ayrılma niyetleri arasındaki ilişkinin incelendiği görülmektedir. Örneğin; Filipinlerde 261 sağlık memurunun katıldığı araştırma sonuçları, sağlık memurlarının COVID-19 korkularının, iş doyumu ile anlamlı düzeyde negatif yönde ve psikolojik sıkıntı, işten ve meslekten ayrılma niyeti ile anlamlı düzeyde pozitif yönde ilişkili olduğunu göstermiştir (Labrague ve de Los Santos, 2021). Bir diğer çalışmada ise Mısır'da görev alan sağlık çalışanlarının COVID-19 korkuları ile iş tatmini ve işten ayrılma niyetleri incelenmiştir. 411 kişinin katılım sağladığı araştırma bulguları, COVID-19 korkusunun iş tatmini ile anlamlı düzeyde negatif yönde ve işten ayrılma niyeti ile anlamlı düzeyde pozitif yönde ilişkili olduğunu göstermiştir (Abd-Ellatif ve ark., 2021). Çin'de otel çalışanları ile yapılan bir diğer araştırma, COVID-19 korkusunun karantina otel çalışanları için olumsuz ruh sağlığı sorunlarına yol açtığını, COVID-19 korkusunun depresyon, anksiyete ve işten ayrılma niyeti ile anlamlı düzeyde ve pozitif yönde ilişkili olduğunu işaret etmiştir (Teng, $\mathrm{Wu}$ ve $\mathrm{Zu}, 2021$ ).

Diğer çalışmalarda ve bu araştırmada COVID-19 korkusu ve işten ayrılma niyetine ilişkin elde edilen bu bulguların, çalışan ruh sağlığının pandemi döneminde çalışanların işlerine yönelik tutumlarını etkilediğine ve işten ayrılma niyetlerindeki rolüne dikkat çekerek mevcut bilgi tabanına katkıda sağladığı görülmektedir. Bu araştırmada elde edilen H1' e ilişkin sonuç, alan yazındaki çalışmalarla benzerlik göstermektedir.

$\mathrm{Bu}$ araştırmada elde edilen bulgular sonucunda COVID-19 korkusu ile işten ayrılma niyeti arasındaki ilişkide psikolojik sermayenin düzenleyici bir rolü olmadığ1 görülmüştür. İkinci hipotez doğrulanmamıştır (H2: COVID-19 ile işten ayrılma niyeti arasındaki ilişkide psikolojik sermaye 
düzenleyici değişkendir. Şöyle $\mathrm{ki}$, psikolojik sermaye yükseldikçe COVID-19 korkusu ve işten ayrılma niyeti arasındaki ilişki azalacaktır).

Maslow'un İhtiyaçlar Hiyerarşisi Kuramı'na $(1943,1954)$ göre güvenlik ihtiyaçlarının giderilmesi bireylerin gelişim yolundaki önemli bir basamaktır. Güvenlik ihtiyaçları; kişisel güvenlik, duygusal güvenlik, ekonomik güvenlik ve kişinin iyi oluşunun güvence altına alınması olarak açıklanmaktadır.

Herzberg ve arkadaşları (1959) tarafından öne sürülen Çift Faktörlü Motivasyon Teorisi'ne göre ise, bireylerin çalıştıkları kurumlarda motive edici faktörler ve hijen faktörler vardır. Motive edici faktörler, bireylerin işten yüksek düzeyde tatmin olmalarına yardımcı olmak için esastır, ancak bunların yokluğu asla bir bireyin işte aşırı derecede tatminsiz olmasına neden olmaz. Tanınma ihtiyacı, başarma ihtiyacı ve kişisel büyüme motive edici faktörler arasındadır. Hijyen faktörler ise, bireylerin işte tatmin olmamalarını durdurmalarına yardımcı olmak için esastır. Ancak en önemlisi, bu faktörler ne kadar büyük olursa olsun, tek başlarına bir bireyin iş yerinde yüksek doyum seviyelerine ulaşmasına asla yardımcı olmazlar. İş yerindeki çalışma koşulları da hijyen faktörler arasındadir.

Alderfer (1972) tarafından öne sürülen ERG Kuramı'na göre ise bireylerin üç temel gereksinimizi bulunmaktadır. Bunlar; varoluşsal, ilişkisel ve bireysel gelişim ihtiyaçlarıdır. Varoluşsal ihtiyaçlar; fiziksel ve güvenlikle ilgili ihtiyaçlar olarak sunulmuştur. Sağlık ve güvenli çalışma koşulları güvenlik ihtiyacı kategorisi içinde olduğu görülmektedir.

İş yaşamına ilişkin bu kuramlardan yola çıkarak, iyi bir çalışan deneyimi ve çalışan bağlllı̆̆1 için güvenlik ihtiyacının ve çalışma koşullarının tatmin edici seviyede olmasının ön koşullar olduğu görülmektedir. Buna karşın, Pandemi sürecinde COVID-19 korkusunun, bireylerin güvenlik ihtiyaçlarını gidermelerinde büyük bir engel oluşturduğu söylenebilir. Bu noktadan yola çıkarak, güvenlik ihtiyacı karşılanamayan bireylerde psikolojik sermayenin koruyucu psikolojik bir faktör olamayacağı düşünülebilir. Ayrıca, bu araştırmada COVID-19 korkusu ile işten ayrılma niyeti arasındaki ilişkide düşük düzeyde anlamlı ilişki bulunması, psikolojik sermayenin bu ilişkide düzenleyici bir rol üstlenmemesinin bir sebebi olabilir. Ayrıca, öğretmenlerin büyük çoğunluğunun uzaktan eğitim vermiş olması ve bu duruma bağlı olarak 
öğretmenlerin psikolojik sermayeyi koruyucu bir kaynak olarak kullanmama ihtimali de psikolojik sermayenin düzenleyici rol üstlenmemesini açıklayan bir faktör olarak değerlendirilebilir.

Önceden de belirtildiği üzere araştırma örneklemi Antalya ilindeki öğretmenlerden oluşmaktadır. Pandemi süreci devam edecek olursa ileride yapılacak araştırmalarda psikolojik sermayenin COVID-19 korkusu ve işten ayrılma niyeti arasındaki ilişkide düzenleyici rolü başka meslek gruplarda da araştırılabilir.

$\mathrm{Bu}$ çalışmada bazı sinırlılıkları bulunmaktadır. Öz-bildirim ölçeklerinin kullanılması sebepli tepki yanlılığı (response bias) problemini ortaya çıkarmış olabilir. Araştırma sonuçları sosyal beğenirlik ihtimalinden etkilenmiş olabilir. Bir diğer sınırlılık ise bağımlı değişken, bağımsız değişken ve düzenleyici değişken için cevaplanan ölçeklerin katılımcıların eş zamanlı olarak alınmasıdır. Bu durum, ölçekler arasındaki ilişkilere ait sonuçların geçerliliği bakımından tehdit oluşturmuş olabilir. 
EXTENDED ABSTRACT

\title{
Teachers' Work Life During Pandemics: Covid-19 Phobia, Intention to Quit Job and Psychological Capital
}

\author{
Hikmet Hakan Coşkun - Merve Mamacı \\ Istanbul Kent University- Fenerbahçe University
}

SARS - CoV -2 Pandemic has affected people emotionally, socially, cognitively and economically as a global health problem (WHO, 2021) since December 2019. The pandemics has also effected the working lives of individuals. During pandemics, individuals with active working life adapted the restrictions and precautions applied to control the pandemic into their working lives.

According to Yamamoto and Altun (2020), the education sector, as well as other sectors, has been affected by the COVID-19 pandemics. To give an example, various precautions have been taken in schools to control the pandemic and prevent transmission. Since it is difficult to comply with the social distance rules in the classrooms and social isolation is a factor preventing transmission, face-to-face education has been suspended and distance education / online education method has been started. On the other hand, although maintaining the education system on an online platform is beneficial in terms of protecting the health system and securing the health of teachers and students, it has come to the fore that education activities cannot continue efficiently with distance learning (TRT, 2020). Based on the efficiency and effectiveness of education, the restrictions in the education sector were re-evaluated and face-to-face education was gradually introduced in the second term of March 2021 in the field of education (MEB, 2021).

In the context of the Covid-19 Vaccine National Implementation Strategy, the vaccination of teachers started on 6 June 2021 (Selçuk, 2021). When the dates of transition to face-to-face education and vaccination are evaluated, it is seen that teachers are not vaccinated while they are actively giving face-to-face training. Also, different difficulties were arised with the gradual reopening of schools after the restrictions. For example, the 
inability to provide adequate isolation in the classroom environment, the possibility of having contacts in the classrooms, and the possibility of asymptomatic COVID-19 cases in the institution or in the classroom may cause fear and anxiety in teachers due to COVID-19. Individuals with specific phobia disorder may hinder their daily functioning by feeling constant and irrational fear of an object or situation that is real or imagined, and by showing avoidance and escape behavior (Eaton et al., 2018; Ruiz-García and Valero-Aguayo, 2020). For this reason, assuming that teachers may feel threatened due to the COVID-19 pandemic and may consider leaving their profession and/or the institutions they are affiliated with, the relationship between teachers' COVID-19 fear levels and their intention to leave was tested in this study.

It is important to investigate the psychological factors that make individuals strong, especially in a difficult periods such as pandemics. One of these factors is psychological capital. Luthans, Luthans, and Luthans (2004) state that psychological capital is a concept beyond other capitals that may be important for the individual and is a positive structure specific to the individual. Based on this definition, it is seen that an individual's psychological capital status is characterized as a combination of four different elements; self-efficacy, optimism, hope, and resilience (Luthans, Youssef, \& Avolio, 2007).

From this point of view, the moderator role of psychological capital in the relationship between fear of COVID-19 and intention to quit was tested.

The findings of the correlation analysis revealed that there is a significant and positive relationship between fear of COVID-19 and intention to leave. In other words, the first hypothesis was confirmed (H1: There is a significant and positive relationship between fear of COVID-19 and turnover intention). It is seen that these findings related to fear of COVID-19 and intention to leave work in other studies and in this research contribute to the existing knowledge base by drawing attention to the fact that employee mental health affects the attitudes of employees towards their work during the pandemic period and its role in turnover intentions. The result of $\mathrm{H1}$ obtained in this study is similar to the studies in the literature. 
As a result of the findings obtained in this study, it was seen that psychological capital did not have a moderating role in the relationship between fear of COVID-19 and intention to leave. The second hypothesis is not confirmed (H2: Psychological capital is the moderator variable in the relationship between COVID-19 and turnover intention). Based on these theories of business life, it is seen that the need for security and satisfactory working conditions are prerequisites for a good employee experience and employee engagement. On the other hand, it can be said that the fear of COVID-19 during the pandemic is a major obstacle for individuals to meet their security needs. From this point of view, it can be thought that psychological capital cannot be a protective psychological factor in individuals whose security needs cannot be met.

\section{Kaynakça / References}

Abd-Ellatif E. E ve ark. (2021). Fear of COVID-19 and its impact on job satisfaction and turnover intention among Egyptian physicians. Safety and Health at Work, https://doi.org/10.1016/j.shaw.2021.07.007.

Ahorsu, D. K., Lin, C. Y., Imani, V., Saffari, M., Griffiths, M. D., ve Pakpour, A. H. (2020). The fear of COVID-19 scale: Development and initial validation. International Journal of Mental Health and Addiction, 27, 1-9.

Alderfer, C. P. (1972). Existence, relatedness, and growth: Human needs in organizational settings. New York: Free Press.

Ataç, A. ve Uçar, M. (2006). Önemli bulaşıcı hastalıklar ve yaşam sürelerine etkileri. Bilim Tarihi Araştırmaları: Salgıı Hastalıklar Tarihi, 2, 33- 42.

Avey, J. B., Luthans, F. ve Jensen, S. M. (2009). Psychological capital: A positive resource for combating employee stress and turnover. Human Resource Management, 48, 677-93.

Avey, J. B., Reichard, R. J., Luthans, F. ve Mhatre, K. H. 2011. Meta-analysis of the impact of positive psychological capital on employee attitudes, behaviors, and performance. Human Resource Development Quarterly, 22, $127-52$.

Chakraborty, K. ve Chatterjee, M. (2020). Psychological impact of COVID-19 pandemic on general population in West Bengal: A cross-sectional study. Indian Journal of Psychiatry, 62, 266-272.

Cho, S., Johanson, M. M. ve Guchait, P. (2009). Employees intent to leave: A comparison of determinants of intent to leave versus intent to stay. International Journal of Hospitality Management,28(3),374-381. 
Çetin, F. ve Basım, H. N. (2012). Örgütsel psikolojik sermaye: Bir ölçek uyarlama çalışması. Amme İdaresi Dergisi, 45(1), 121-137.

Eaton, W. W., Bienvenu, O. J., ve Miloyan, B. (2018). Specific phobias. Lancet Psychiatry, 5(8), 678-686.

Elmas, S. (2012). İşyerinde mobbing ve çalışanların işten ayrılma niyeti üzerine etkilerine ilişkin bir araştırma. Yayımlanmamış Yüksek Lisans Tezi. İstanbul Üniversitesi, Sosyal Bilimler Enstitüsü, İşletme Anabilim Dalı.

Estiri, M., Nargesian, A., Dastpish, F. ve Sharifi, S. M. (2016). The impact of psychological capital on mental health among Iranian nurses: Considering the mediating role of job burnout. SpringerPlus, 5(1), 1377.

Ghapanchi, A. H. ve Aurum, A. (2011). Antecedents to IT personnel's intentions to leave: A systematic ure review. Journal of Systems and Software, 84(2), 238-249.

Griffeth, R.W., Hom, P.W. ve Gaertner, S. (2000). A meta-analysis of antecedents and correlates of employee turnover: Updated moderator tests, and research implications for the next millennium. Journal of Management, 26, $463-488$.

Heinen, M. M., van Achterberg, T., Schwendimann, R., Zander, B., Matthews, A., Kózka, M., ve Schoonhoven, L. (2013). Nurses' intention to leave their profession: A cross sectional obser- vational study in 10 European countries. International Journal of Nursing Studies, 50(2), 174-184.

Herzberg, F., Mausner, B., ve Snyderman, B. (1959). The motivation to work. NY: John Wiley \& Sons.

Hom, P.W., Caranikas-Walker, F., Prussia, G.E. ve Griffeth, R.W. (1992). A Meta-Analytical structural equations analysis of a model of employee turnover. Journal of Applied Psychology, 77, 890-909.

Hoppock, R. (1935). Job satisfaction. Harper and Brothers: New York.

Hu, T., Zhang, D., ve Wang, J. (2015). A meta-analysis of the trait resilience and mental health. Personality and Individual Differences, 76, 18-27.

Joseph, D., Ng, K.Y., Koh, C. ve Ang, S. (2007). Turnover of information technology professionals: A narrative review, meta analytic structural equation modeling, and model development. MIS Quarterly, 31(3), 547577.

Labrague L.J. ve de Los Santos J. A. A. (2021). Fear of COVID-19, psychological distress, work satisfaction and turnover intention among frontline nurses. Journal of Nursing Management, 29, 395-403. 
Last, J. M (2001). A Dictionary of Epidemiology (4th ed.) New York: Oxford University Press.

Lee, T. W. ve Mitchell, T. R. (1994). An alternative approach: The unfolding model of voluntary employee turnover. The Academy of Management Review, 19(1), 51-89.

Li W., Yang Y., Liu Z.-H., Zhao Y.-J., Zhang Q., Zhang L., Cheung T., Xiang Y.T. (2020). Progression of mental health services during the COVID-19 outbreak in China. International Journal of Biological Sciences, 16, 17321738.

Luthans, F., Luthans, K. W., ve Luthans, B. C. (2004). Positive psychological capital: Beyond human and social capital. Business Horizon, 41(1), 45-50.

Luthans, F., Avolio, B. J., Avey, J. B., ve Norman, S. M. (2007). Positive psychological capital: Measurement and relationship with performance and satisfaction. Personnel Psychology, 60, 541-572.

Luthans, F., Youseff, C.M. ve Avolio, B. J. (2007). Psychological capital: Investing and developing positive organizational behavior. D. Nelson ve C. L. Cooper içinde, Positive Organizational Behavior (s.9-24). Thousand Oaks, C.A: Sage.

Maslow, A. H. (1943). A theory of human motivation. Psychological Review, 50(4), 370-96.

Maslow, A. H. (1954). Motivation and personality. New York: Harper and Row.

Masroor A.M. ve Fakir M. J. (2010). Level of job satisfaction and intent to leave among Malaysian nurses. Business Intelligence Journal, 3(1), 123-137.

Mello, J. A. (2011). Strategic management of human resources. Canada: Nelson Education.

Meyer, J. P., Allen, N. J. ve Allen, N.J. (1997). Commitment in the workplace. CA: Sage Publications.

Milli Eğitim Bakanlığı. (2021, Şubat 14). 2020-2021 Eğitim ve öğretim yılının ikinci dönemi uzaktan ve yüz yüze eğitimle başlıyor. https://www.meb.gov.tr/2020-2021-egitim-ogretim-yilinin-ikinci-donemiuzaktan-ve-yuz-yuze-egitimle-basliyor/haber/22553/tr.

Mobley, W. H., Griffeth, R. W., Hand, H. H., ve Meglino, B. M. (1979). Review and conceptual analysis of the employee turnover process. Psychological Bulletin, 86(3), 493-522.

Moynihan, D. P., ve Landuyt, N. (2008). Explaining turnover intention in State Government examining the roles of gender, life cycle, and loyalty. Review of Public Personnel Administration, 28(2), 120-143. 
Nancarrow, S., Bradbury, J., Pit, S. W., ve Ariss, S. (2014). Intention to stay and intention to leave: Are they two sides of the same coin? A crosssectional structural equation modelling study among health and social care workers. Journal of Occupational Health, 56(4), 292-300.

Rosin, H. ve Korabick, K. (1995). Organisational experiences and propensity to leave a multivariate investigation of men and women managers. Journal of Vocational Behaviour, 46(1), 1-16.

Ruiz-García, A., ve Valero-Aguayo, L. (2020). Multimedia intervention for specific phobias: A clinical and experimental study. Psicothema, 32(3), 298-306.

Rusbult, C. E., Farrell, D., Rogers G. ve Mainous III, A. G. (1988). Impact of exchange variables on exit, voice, loyalty, and neglect: An integrative model of responses to declining job satisfaction. Academy of Management Journal, 31(3), 599-627.

Selçuk, Z. [@ziyaselcuk]. (2021, Haziran 6). Tüm öğretmenlerimizin ve eğitim çalışanlarımızın aşı randevuları Sağlık Bakanlığı tarafından tanımlandı. Mesai arkadaşlarımız an itibarıyla randevularını eNabız'dan alabilirler. Eğitim ailemiz adına tüm sağlık camiamıza teşekkürlerimi sunuyorum. [Tweet].Twitter. https://twitter.com/ziyaselcuk/status/1401475213506891776?s=24.

Seligman, M. E. P ve Csikszentmihalyi, M. (2000). Positive psychology: An introduction. American Psychologist, 55, 5-14.

Sintema, E. J. (2020). Effect of COVID-19 on the performance of grade 12 students: Implications for STEM education. Eurasia Journal of Mathematics, Science and Technology Education, 16(7), em1851.

Tabachnick, B. G. ve Fidell, L. S. (2013). Using multivariate statistics (6th ed.), Boston: Allyn and Bacon.

Tanner, C. (2020, Haziran 6). When coronaphobia turns into agoraphobia: 'I struggle to even go out for a walk' Erişim tarihi 6 Haziran. 2021 https://inews.co.uk/news/coronavirus-uk-latest-lockdown-restrictionscoronaphobia-agoraphobia-mental-health-434506.

Teng, Y., Wu, K. ve Zu, D. (2021). The association between fear of Coronavirus disease 2019, mental health, and turnover intention among quarantine hotel employees in China. Frontiers in Public Health, 9, 557- 567.

Tett, R. P. ve J. P. Meyer. (1993). Job satisfaction, organizational commitment, turnover intention and turnover: Path analyses based on meta- analytic findings. Personnel Psychology, 46(2), 259-293. 
TRT. (2020, 17 Kasım). Milli Eğitim Bakanlığından uzaktan eğitim aç1klaması.https://www.trthaber.com/haber/gundem/milli-egitimbakanligindan-uzaktan-egitim-aciklamasi-531820.html.

Turliuc, M.N. ve Candel, O.S. (2021). The relationship between psychological capital and mental health during the Covid-19 pandemic: A longitudinal mediation model. Journal of Health Psychology, https://doi.org/10.1177/13591053211012771.

WHO (2021, 21 Haziran). WHO Coronavirus Disease (COVID-19) Dashboard I WHO Coronavirus Disease (COVID-19) Dashboard. Erişim tarihi 22. Haziran.2021 https://covid19.who.int/.

Yamamoto, G. T ve Altun, D. (2020). The Coronavirus and the rising of online education. Journal of University Studies, 3(1), 25-34.

\section{Kaynakça Bilgisi / Citation Information}

Coşkun, H. H. ve Mamacı, M. (2021). Pandemi döneminde öğretmenlerin iş yaşamı: Covid-19 fobisi, işten ayrılma niyeti ve psikolojik sermaye. OPUS-Uluslararası Toplum Araştırmaları Dergisi, 18(44), 7912-7934. DOI: 10.26466/opus.962907. 